\title{
Design of Multicarrier Broadband Power Line Communication System for Tanzania Homes
}

\author{
Crallet Victor \\ College of Informatics and Virtual Education \\ The University of Dodoma \\ Dodoma, Tanzania
}

\author{
Nixon Mtonyole \\ College of Informatics and Virtual Education \\ The University of Dodoma \\ Dodoma, Tanzania
}

\begin{abstract}
Broadband Power Line Communication (BPLC) is a method of providing broadband internet access to consumers using High Frequency (HF) radio signals coupled into the mains power wiring. In the BPLC system, data signals are modulated at HF and injected into the power lines using broadband modulation techniques. Design of a BPLC system requires a complete understanding of the Power line network (PLN) topologies involved. PLN can be classified as Indoor or In-home, Low voltage, Medium voltage and High voltage respectively. In this study four maps representing typical Tanzania houses were selected randomly, and then four indoor power-line networks were derived from their circuit diagrams. The Impulse response was estimated at the switch sockets using the recent power-line channel model by Anatory et al. The delay spread estimated from the impulse response was used to design the OFDM system and the OFDM system performance was evaluated.
\end{abstract}

\section{General Terms}

Indoor Power Line Communications, Anatory et. al.

Keywords

BPLC, PLN, OFDM

\section{INTRODUCTION}

The basic idea of multicarrier modulation is to divide the transmitted bit stream into many different sub streams and send these over many different sub channels [1]. Typically the sub channels are orthogonal under ideal propagation conditions. The data rate on each of the sub channels is much less than the total data rate, and the corresponding sub channel bandwidth is much less than the total system bandwidth. The number of sub streams is chosen to ensure that each sub channel has a bandwidth less than the coherence bandwidth of the channel, so that sub channels experience relatively flat fading [2]. This reduces ISI on each sub channel. The sub channels in multicarrier modulation need not be contiguous, so a large continuous block of spectrum is not needed for high rate multicarrier communication.

Multicarrier modulation is efficiently implemented digitally. In this discrete implementation, called OFDM, the ISI can be completely eliminated through the use of a cyclic prefix. According to [3] multicarrier modulation is used in systems operating in communication channels which are frequency selective due to multipath effects. Indoor power-line channels found in Tanzania are also frequency selective [4]. Frequency selectivity of the Tanzania indoor power-line channels can be modeled as a time varying-outlet location dependent channel with multipath effects caused by reflections due to impedance mismatches and branch interconnections.

\section{TYPICAL INDOOR POWER-LINE NETWORKS FOR TANZANIA}

Tanzania indoor power-line networks have the circuits that begin at the distribution function block (DFB) which represents the main switch or distribution miniature circuit breaker (see Figure 1 - 4). Different circuits that can be found are; light circuit(s), switch socket circuit(s), heater circuit(s) and cooker circuit(s). Circuits are characterized by the conductor cross sectional area and the separation between the line and adjacent return conductor (neutral). Conductor cross sectional area and the diameter of the polyvinyl chloride (PVC) conduit for this study were taken to be, $1.5 \mathrm{~mm}$ and for light circuits, $2.5 \mathrm{~mm}$ for switch socket circuits, $4 \mathrm{~mm}$ for heater circuits and $6 \mathrm{~mm}$ for cooker circuits. As shown in the Figure 1-4, from the distribution function block (TX location) the indoor power-line network consists of different circuits depending on whether current ratings of electrical equipment are taken into account.

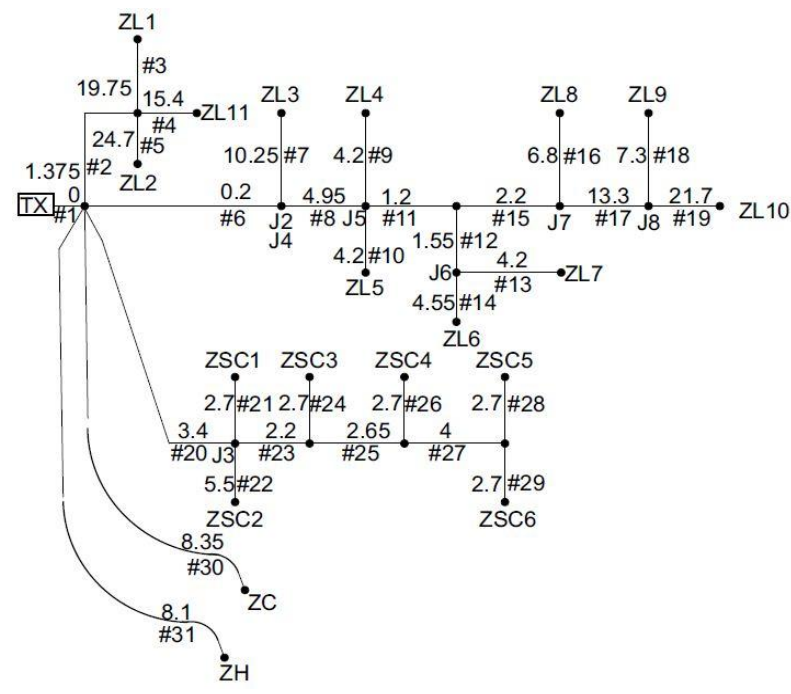

Fig 1: Indoor power-line network for house 1 


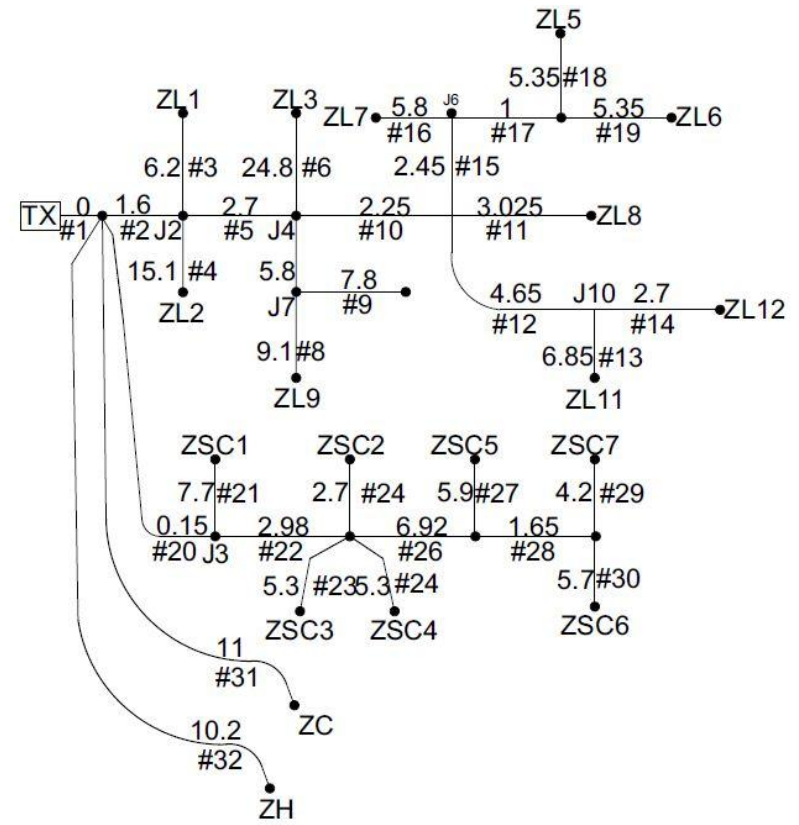

Fig 2: Indoor power-line network for house 2

Numbers in vertical and horizontal branches represent branch length and branch ID. In determining the impulse response for each topology the power-line channel model by Anatory et al was used. The receiver terminals were located at the switch sockets for each topology.

\section{IMPULSE RESPONSE OF AN INDOOR POWER-LINE NETWORK}

To be able to design a communication system using typical Tanzania indoor power-line network based on multicarrier modulation, channel delay spread must be determined first. From the circuit diagram of each map the impulse response was estimated at the switch sockets using the recent powerline channel model by Anatory et al. The model is given in (1a) [5]. Equation (2.1) [5] gives the transfer function between any load point (receiver location) and the sending end (transmitter location).

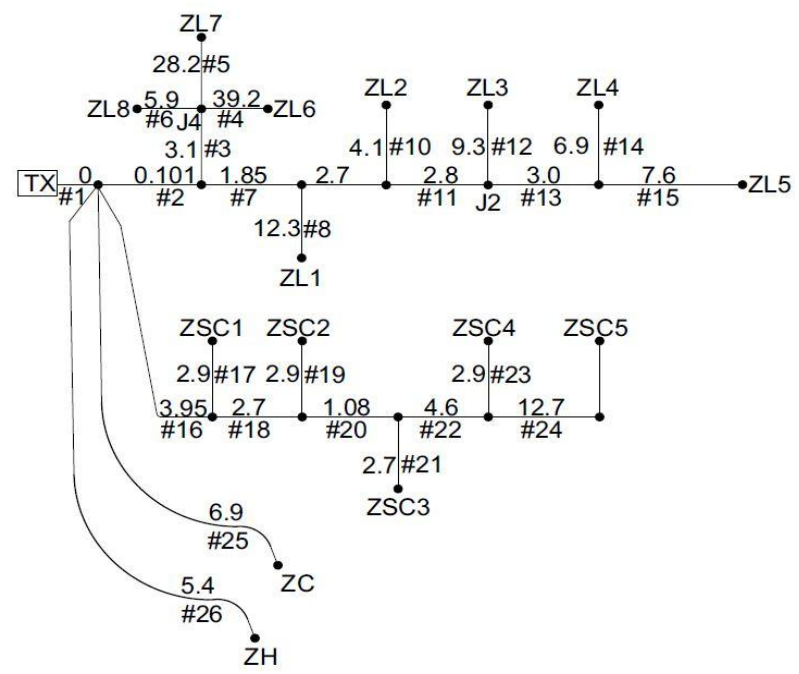

Fig 3: Indoor power-line network for house 3
During the impulse response determination; the transmitter was placed at the distribution function block that includes all the system (with all branches included) and the receiver side was placed at the switch sockets, the loads where either terminated at low or high impedances because in PLN it has been shown that the maximum delay spread occurs for cases when the channel is terminated either in low impedances or high impedances [6].

The most common insulation material of low voltage power cables for Tanzania indoor power-line network is PVC. However, it is not practical to define any general dielectric characteristics of the PVC. This is because the characteristics of the PVC depend heavily on the factors like temperature, frequency and the exact

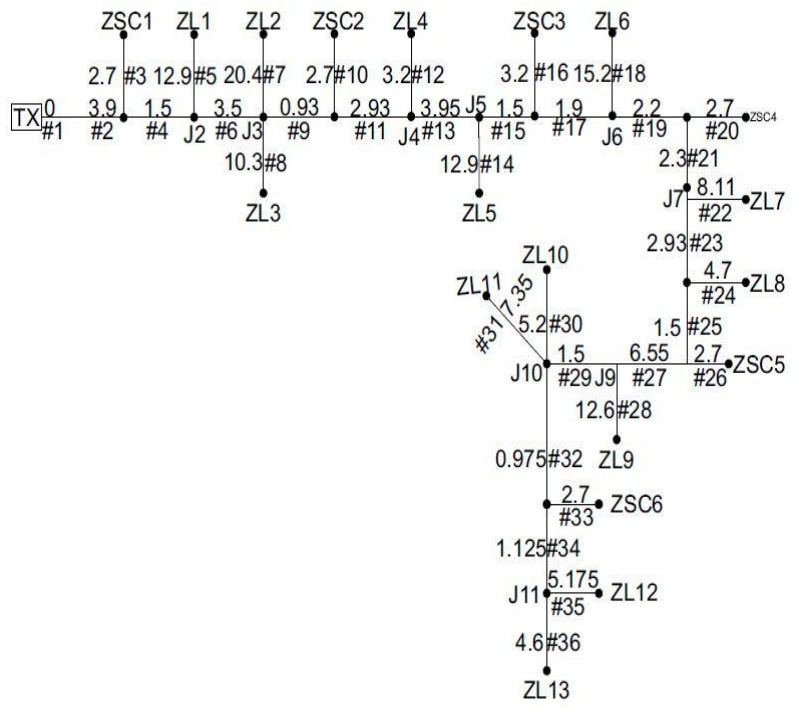

Fig 4: Indoor power-line network for house 4 composition of the insulation material [12].

Fig. 5 shows the relationship between dielectric constant, frequency, and temperature.

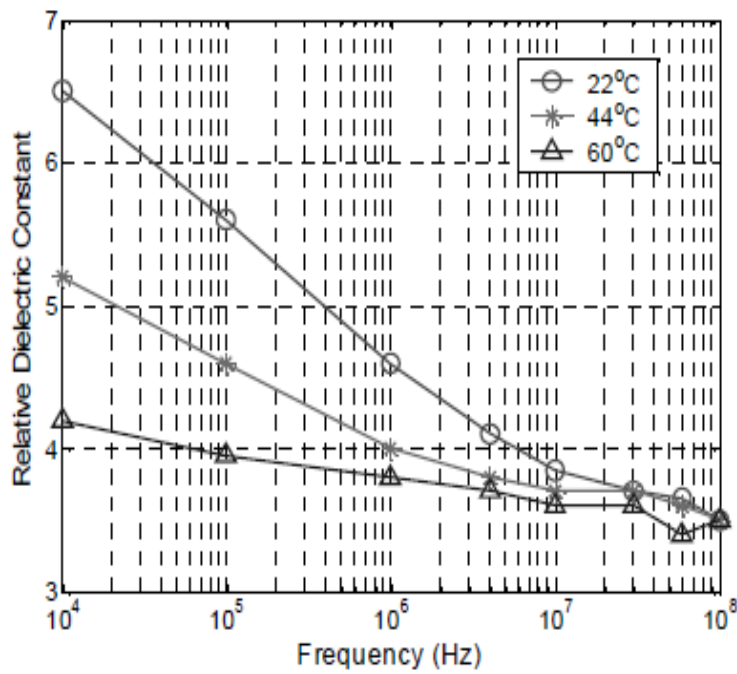

Fig 5: Relationship of the dielectric constant, frequency and temperature [12] 
Due to the fact that it is not practical to define any general dielectric characteristics of the PVC for this study \&r was taken to be 4.75 and $\mu \mathrm{r}$ was taken to be 1 . Also because in a real transmission line attenuation caused by $\mathrm{R}$ and $\mathrm{G}$ is much less than by $\mathrm{L}$ and $\mathrm{C}$, i.e. $\mathrm{R}<<\omega \mathrm{L}$ and $\mathrm{G}<<\omega \mathrm{C}$, then the lossless case was considered. The per unit length inductances, capacitances, characteristic impedances and propagation constants for a lossless case were found using;

$L=(\mu / \pi) \cosh ^{-1}(D / 2 a)[H]$

$C=\frac{\pi \varepsilon}{\cosh ^{-1}\left({ }^{D} / 2 a\right)}[F / M]$

$Z=\sqrt{\frac{L}{C}}$

$\gamma=\alpha+j \beta=j \omega \sqrt{L C}$

The parameter $\mu$ is permeability of the dielectric material, $\mathrm{D}$ is the cable diameter (or separation between live and neutral), a is radius of conductor and $\varepsilon$ is permittivity of the dielectric medium.

During impulse response determination the transmitter was a $2 \mathrm{~V}$ rectangular pulse, with $0.9 \mu$ s pulse width and shifted by $0.1 \mu \mathrm{s}$. This rectangular pulse was then applied to the Tanzania indoor power-line network with source impedance terminated in characteristic impedance. After finding the channel transfer function in frequency domain, the signal response in frequency domain was determined using (2) [5] at the switch sockets where the receiver is located.

Finally the impulse response was found by Inverse Fourier Transform. In all cases source impedance was $85 \Omega$.

\section{TYPICAL IMPULSE RESPONSES FOR TANZANIA HOME POWER-LINES NETWORKS}

The following Figures depict the impulse responses at various terminals for each house. For each house the impulse responses were determined at various terminals all terminated in $10 \Omega$ and $100 \mathrm{k} \Omega$ respectively. And for all analyses the source impedance was $85 \Omega$.

Consideration of all impulse responses displayed by Figures 6-9 showed that the maximum delay spread (time span of channel impulse response) $\mathrm{Tm}$ was about $2 \mu \mathrm{s}$. This is because according to

Figures 6(a)-9(a) channel amplitudes at low impedances were very smaller hence contributing less to channel amplitude fluctuations.
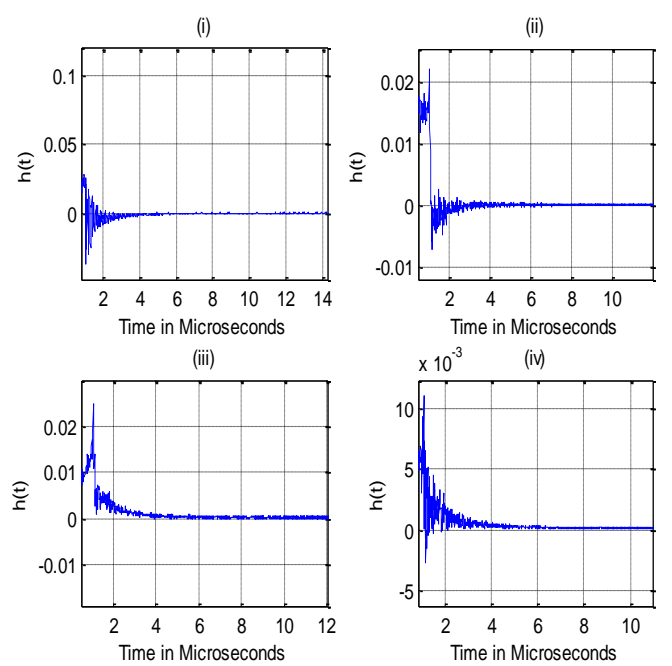

Fig 6(a) House 1 impulse response at various loads (all

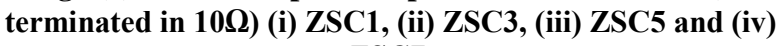
ZSC7.
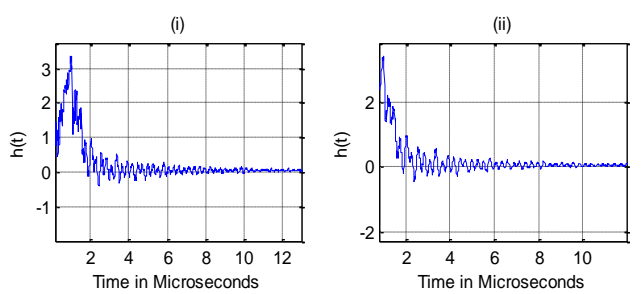

(iii)
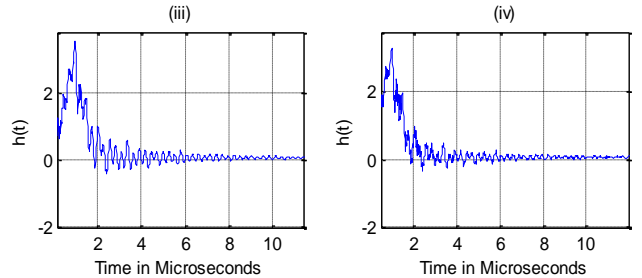

Fig 6(b): House 1 impulse response at various loads (all terminated in $100 \mathrm{k} \Omega$ ) (i) $\mathrm{ZSC1}$, (ii) $\mathrm{ZSC3}$, (iii) $\mathrm{ZSC} 5$ and (iv) ZSC7.
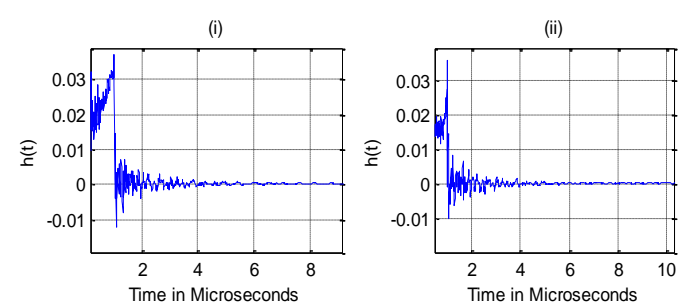

(iii)
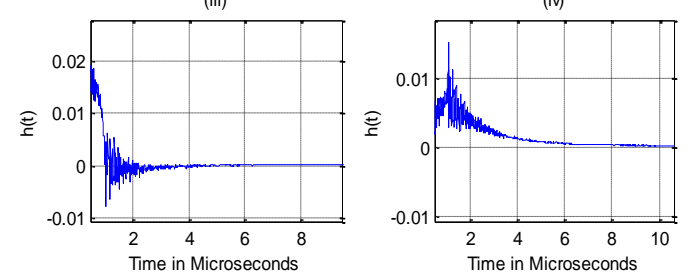

Fig 7(a): House 2 impulse response at various loads (all

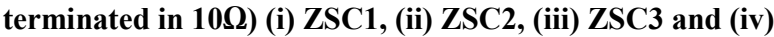
ZSC5 

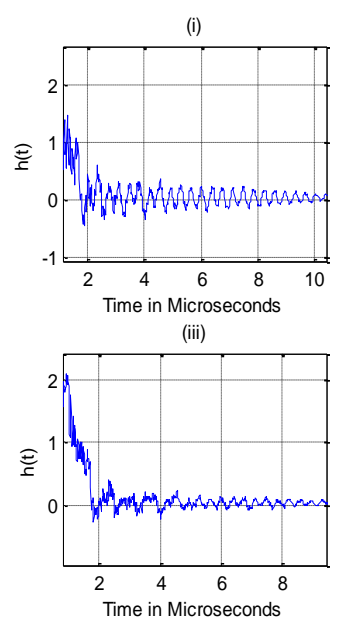
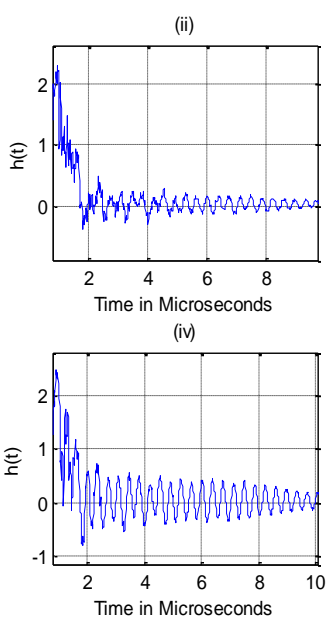

Fig 7(b): House 2 impulse response at various loads (all terminated in $100 \mathrm{k} \Omega$ ) (i) $\mathrm{ZSC} 1$, (ii) $\mathrm{ZSC} 2$, (iii) $\mathrm{ZSC} 3$ and (iv)ZSC5
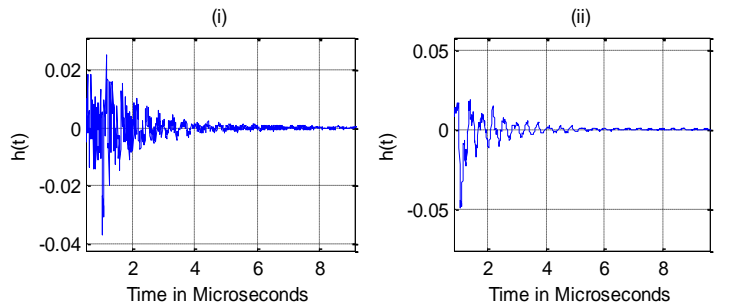

(iii)
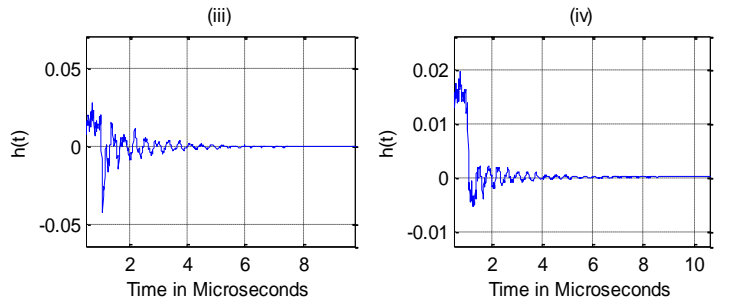

Fig 8(a): House 3 impulse response at various loads (all

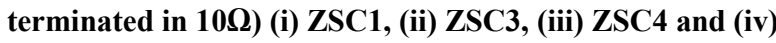
ZSC5

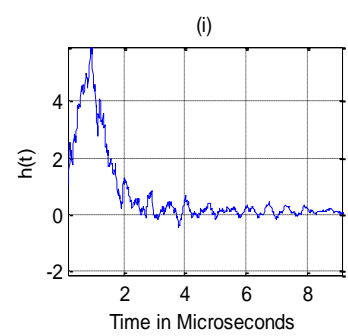

(iii)

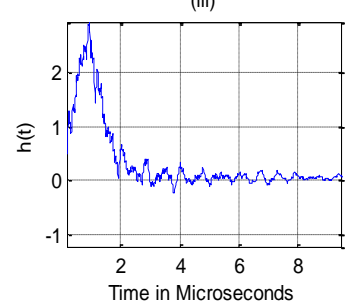

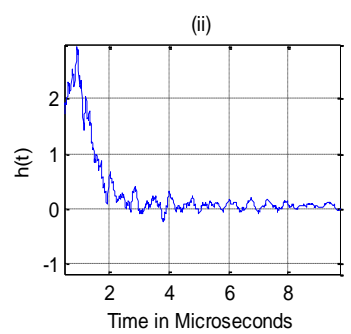

(iv)

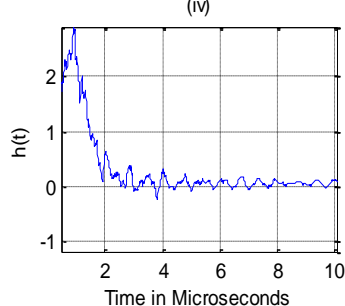

Fig 8(b): House 3 impulse response at various loads (all terminated in $100 \mathrm{k} \Omega$ ) (i) $\mathrm{ZSC1}$, (ii) $\mathrm{ZSC3}$, (iii) $\mathrm{ZSC} 4$ and (iv) ZSC5
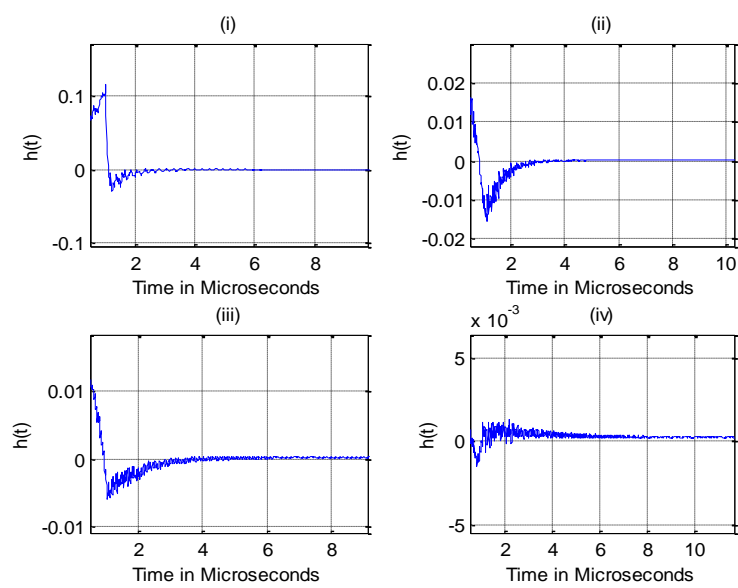

Fig 9(a): House 4 impulse response at various loads (all

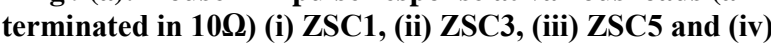
ZSC6
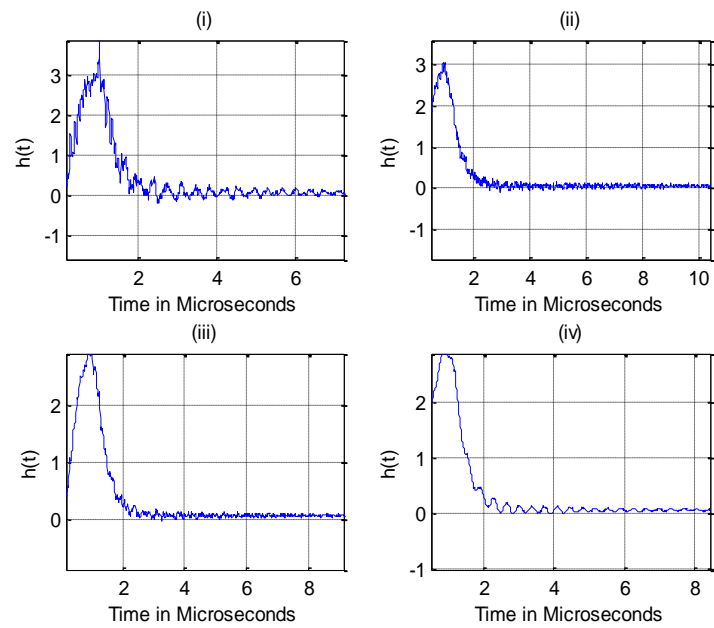

Fig 9(b): House 4 impulse response at various loads (all terminated in $100 \mathrm{k} \Omega$ ) (i) $\mathrm{ZSC1}$, (ii) $\mathrm{ZSC3}$, (iii) ZSC5 and (iv) ZSC6

\section{OFDM SYSTEM DESIGN}

An OFDM system with total frequency band $\mathrm{B}=16.5 \mathrm{MHz}$ was considered. Since the number of sub-channels $\mathrm{N}$ has to be chosen in such a way that the symbol time in each subchannel is greater than the delay spread of the channel so as to combat ISI (sub-channel bandwidth is less than the channel coherence bandwidth), then given the maximum delay spread of $2 \mu \mathrm{s}$, the channel coherence bandwidth $\mathrm{Bc}$ was $\mathrm{Bc}=1 / \mathrm{Tm}$ $=1 / 2 \mu \mathrm{s}=0.5 \mathrm{MHz}$. To insure flat-fading on each sub channel $\mathrm{BN}=\mathrm{B} / \mathrm{N}=0.1 * \mathrm{Bc}$.

Where $\mathrm{B}$ is the total bandwidth and $\mathrm{Bc}$ is the coherence bandwidth. Thus, $\mathrm{N}=\mathrm{B} / 0.1 * \mathrm{Bc}=16.5 \mathrm{MHz} /(0.1 * 0.5 \mathrm{MHz})=$ 330 sub channels are needed to insure flat-fading on each sub channel.

In discrete implementations of multicarrier $\mathrm{N}$ must be a power of two for the DFT and IDFT operations, in which case $\mathrm{N}=$ 512 for this set of parameters [6]. So the OFDM symbol duration was $\mathrm{TN}=1 / \mathrm{BN}=\mathrm{N} / \mathrm{B}=512 / 16.5 \mathrm{MHz}=31.03 \mu \mathrm{s}$ 
which is more than the delay spread of the channel hence ISI between OFDM symbols is removed. But the orthogonality of sub channels in OFDM cannot be maintained. This is because individual sub channels cannot be completely separated by using an FFT circuit at the receiver due to adjacent intersymbol interference (AISI) introduced by transmission channel distortions. To reduce the (AISI) distortion, a simple solution is to increase the symbol duration or the number of carriers. However, this method may be difficult to implement in terms of carrier stability against Doppler frequency and FFT size.

A practical way to eliminate AISI between adjacent OFDM symbols is to create a cyclically extended guard interval called a cyclic prefix. This way each OFDM symbol is preceded by a periodic extension of the signal itself. The total symbol duration becomes $\mathrm{T}=\mathrm{TN}+\mathrm{TG}$.

Where TG, is the guard interval (Cyclic prefix). With a cyclic prefix included each symbol is made of two parts. The whole signal is contained in the active symbol, the last part of which is also repeated at the start of the symbol and is called a guard interval or cyclic prefix. When the guard interval is longer than the channel impulse response, or the multipath delay, the effect of AISI can be eliminated. However, the intercarrier interference (ICI), or in-band fading, still exists [8].

The length of the cyclic prefix was set to $\mu=64 \gg>\mathrm{Tm} / \mathrm{Ts}=2 * 16.5=33$ to insure no ISI between adjacent OFDM symbols.

All design parameters of the OFDM system are summarized in Table 1.

Table 1: OFDM system parameters

\begin{tabular}{|c|l|l|}
\hline No. & \multicolumn{1}{|c|}{ Parameter } & \multicolumn{1}{c|}{ Value } \\
\hline 1. & Total Bandwidth (B) & $16.5 \mathrm{MHz}$ \\
\hline 2. & Coherence Bandwidth $(\mathrm{Bc})$ & $0.5 \mathrm{MHz}$ \\
\hline 3. & Number of Channels $(\mathrm{N})$ & 512 \\
\hline 4. & Modulation & BPSK, OFDM \\
\hline 5. & Symbol Duration $(\mathrm{TN})$ & $34.91 \mu \mathrm{s}$ \\
\hline 6. & Cyclic Prefix $(\mu)$ & 64 \\
\hline 7. & Guard Interval & $3.88 \mu \mathrm{s}$ \\
\hline 8. & Sub-channel Bandwidth $(\mathrm{BN})$ & $32.22 \mathrm{KHz}$ \\
\hline 9. & Data Rate (BPSK) & $1.67 \mathrm{bps}$ \\
\hline
\end{tabular}

\section{BIT ERROR RATE EXPRESSIONS FOR UN-CODED OFDM}

The performance indication of any modulation scheme in any communication channel is through bit error rate performance. The channel impulse response of the power-line is given as in (5) and it can be expanded to appear as in (6). The corresponding sub-channel response is given in (7).

$$
h(t, \tau)=\sum_{i=0}^{L-1} h_{i}(t) \delta\left(t-\tau_{i}\right)
$$

$$
\begin{aligned}
& h(t, \tau)=h_{0}+h_{1} \delta\left(t-\tau_{1}\right)+h_{2} \delta\left(t-\tau_{2}\right)+ \\
& h_{3} \delta\left(t-\tau_{3}\right)+. .+h_{L-1} \delta\left(t-\tau_{L-1}\right)
\end{aligned}
$$

$$
H_{k}=h_{0}+h_{1} e^{-\pi \frac{k}{N}}+h_{2} e^{-\pi \frac{2 k}{N}}+h_{3} e^{-\pi \frac{3 k}{N}}+e^{-\pi \frac{4 k}{N}}
$$

For instance assuming the power-line channel with impulse response as in (3.12);

$$
\begin{aligned}
h(t, \tau)=0.7 \delta(t) & +0.25 \delta\left(t-0.5 T_{b}\right) \\
+ & 0.7 \delta\left(t-1.5 T_{b}\right)+0.5 \delta(t \\
& \left.-3 T_{b}\right)
\end{aligned}
$$

Then the corresponding sub-channel response is as in (9);

$$
H_{k}=0.7-0.25 e^{-\pi \frac{k}{N}}+0.7 e^{-\pi \frac{3 k}{N}}+0.5 e^{-\pi \frac{6 k}{N}}
$$

The OFDM system may be implemented by using BPSK or QPSK or M-QAM. The BER performance of a PLC-OFDM based system under BPSK, QPSK and M-QAM is given by (10-13) respectively. In (10-13) the parameters $\mathrm{Eb}, \mathrm{Nm}, \mathrm{Hk}$ and $\mathrm{N}$ represent the energy signal, noise power, sub-channel response and number of sub-channels respectively. The parameters TN and Tguard are information time and guard time [1].

$$
\begin{aligned}
& P_{b k}=\frac{1}{N} \sum_{k=0}^{N-1} Q\left[\sqrt{\frac{2\left|H_{k}\right|^{2} a_{g} E_{b}}{N_{m}}}\right] \\
& P_{b k}=\frac{1}{N} \sum_{k=0}^{N-1} 2 Q\left[\sqrt{\frac{2\left|H_{k}\right|^{2} a_{g} E_{b}}{N_{m}}}\right]-Q^{2}\left[\sqrt{\frac{2\left|H_{k}\right|^{2} a_{g} E_{b}}{N_{m}}}\right]
\end{aligned}
$$

$$
P_{b k}=\frac{1}{N} \sum_{k=0}^{N-1} 4\left[1-\frac{1}{\sqrt{M}}\right] * Q\left[\sqrt{\frac{3 \log _{2} M\left|H_{k}\right|^{2} a_{g} E_{b}}{(M-1) N_{m}}}\right]
$$

$a_{g}=\frac{T_{N}}{T_{N}+T_{\text {guard }}}$

In this study equation 10 and 13 were used for evaluating the performance of the PLC-OFDM system with BPSK modulation using MATLAB simulations. During the simulations $\mathrm{Hk}$ was derived from the typical impulse responses of the four Tanzania home power-line networks as discussed above. Nm represented noise power as it's 
explained in [5].The remaining parameters were obtained from the OFDM parameters in Table 1.

\section{OFDM SYSTEM PERFORMANCE ANALYSIS}

The home power-line networks have different topologies which are governed by the location of loads within a room and number of rooms. Different numbers of rooms add branches to the power-line network. Types of equipments used in house influence load impedance which varies with frequency. The distance between junction boxes dictates the branch length and hence all these affect the performance of the channel. To determine the influence of branches, branch length and load impedance the power line configurations from four houses were selected. The transmitter was placed at the main switch while the receiver was located at the switch sockets. The transmitter was terminated in line characteristics impedance while the receiver was terminated at $50 \Omega$ and $10 \mathrm{k} \Omega$ for low and high impedance analyses respectively.

\subsection{Influence of Low Impedance, Number of} Branches and Branch Length

First the home power-line network 1 was considered. The transmitter was at node 1 just after the main switch. Fig. 1013 shows the performance of the four home power-line channels at different terminals, terminated at $50 \Omega$ for each house. It is observed that for all four home power-line channels the good performance is obtained at ZSC1 because it is close to the transmitter. The good performance of 10-10 is obtained at the load ZSC1 at SNR per bit of $42.5 \mathrm{~dB}, 42 \mathrm{~dB}$, $32.5 \mathrm{~dB}$ and $41 \mathrm{~dB}$ for HPLN 1, HPLN 2, HPLN 3 and HPLN 4 respectively. The performance at the other nodes is degraded due to number of branches between transmitting and receiving ends.

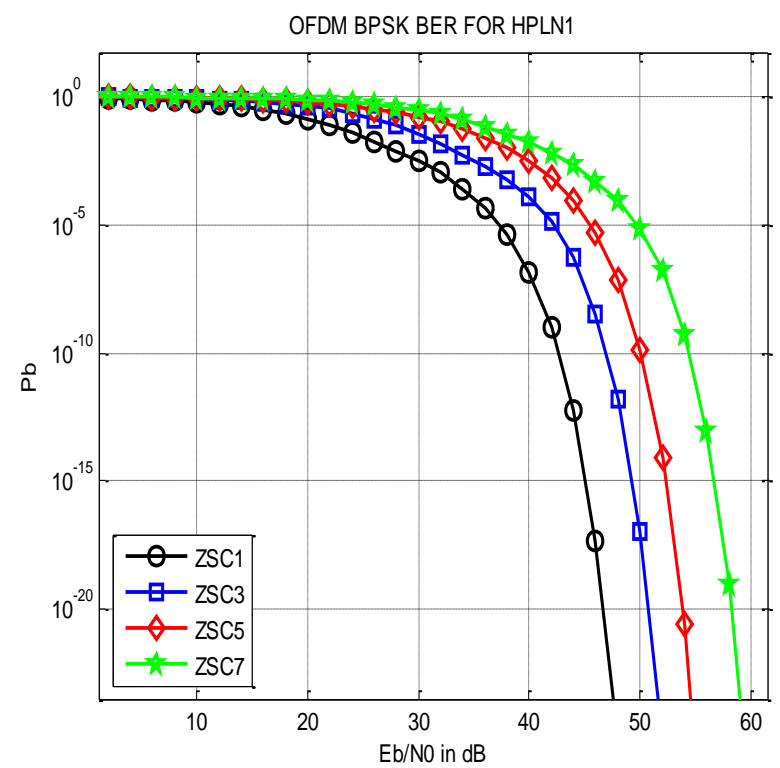

Fig 10: HPLN 1 simulation results at different loads (all

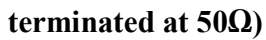

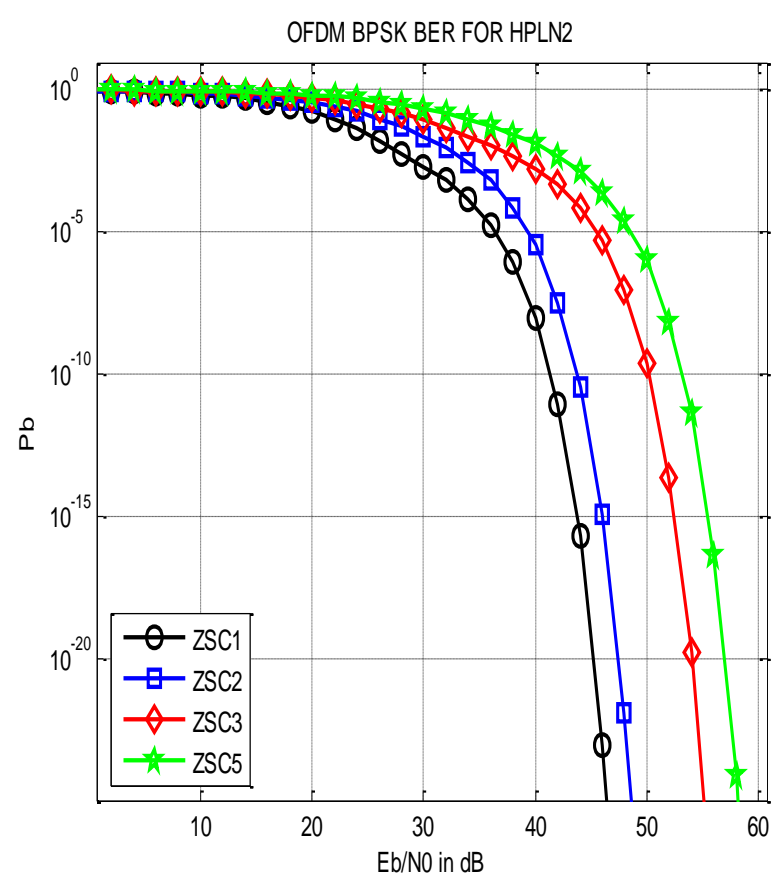

Fig 11: HPLN 2 simulation results at different loads (all terminated at $50 \Omega$ )

\subsection{Influence of High Impedance, Number of Branches and Branch Length}

Fig. 14-17 shows the performance of the four home powerline channels at different terminals, terminated at $10 \mathrm{k} \Omega$ for each house. Again it is observed that for all four home powerline channels the good performance is obtained at $\mathrm{ZSC1}$ because it is close to the transmitter.

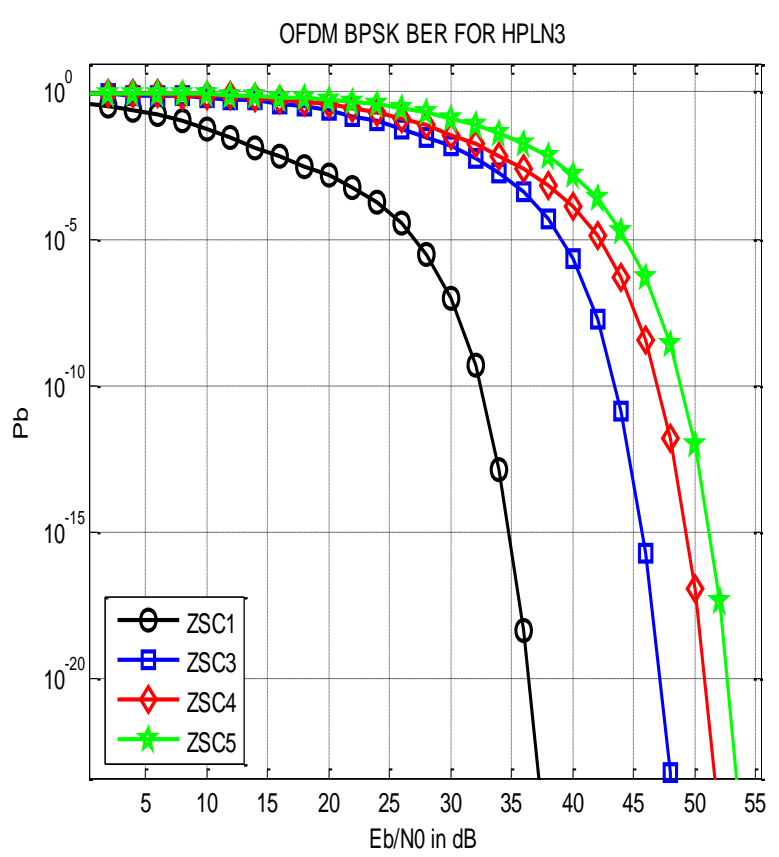

Fig 12: HPLN 3 simulation results at different loads (all

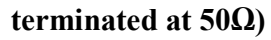




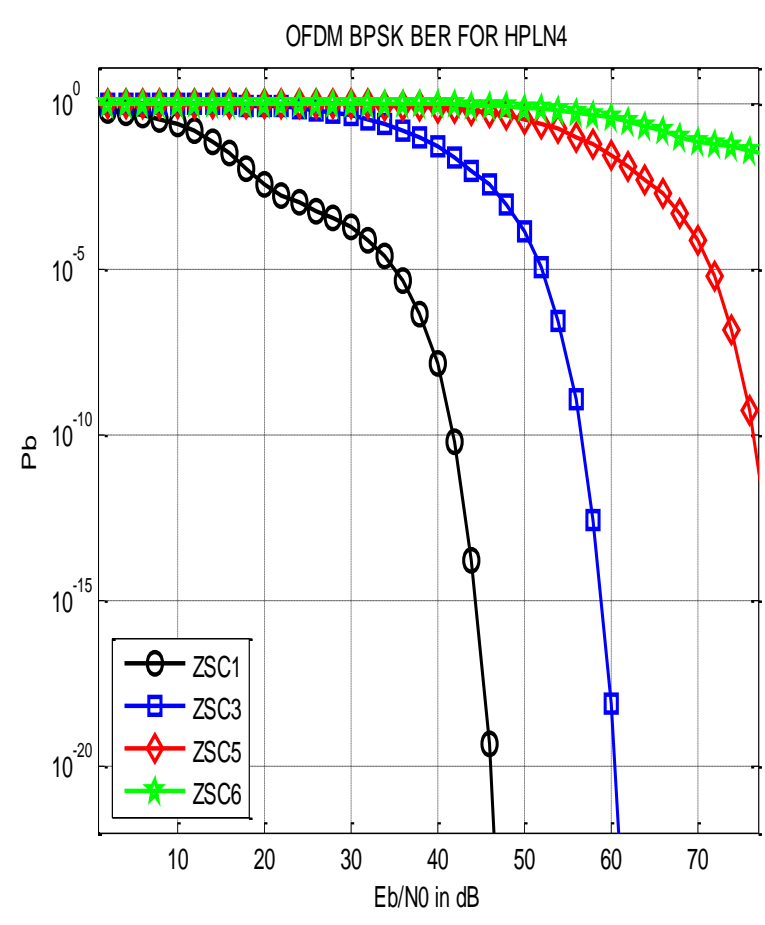

Fig 13: HPLN 4 simulation results at different loads (all

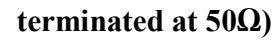

The good performance of $10-10$ is obtained at the load ZSC1 at SNR per bit of $67 \mathrm{~dB}$ and $76 \mathrm{~dB}$ for HPLN 1 and HPLN 4 respectively. For HPLN2 and HPLN 3 to achieve the good performance of 10-10 at least SNR per bit of $80 \mathrm{~dB}$ is required. The performance at the other nodes is degraded due to number of branches between transmitting and receiving ends.

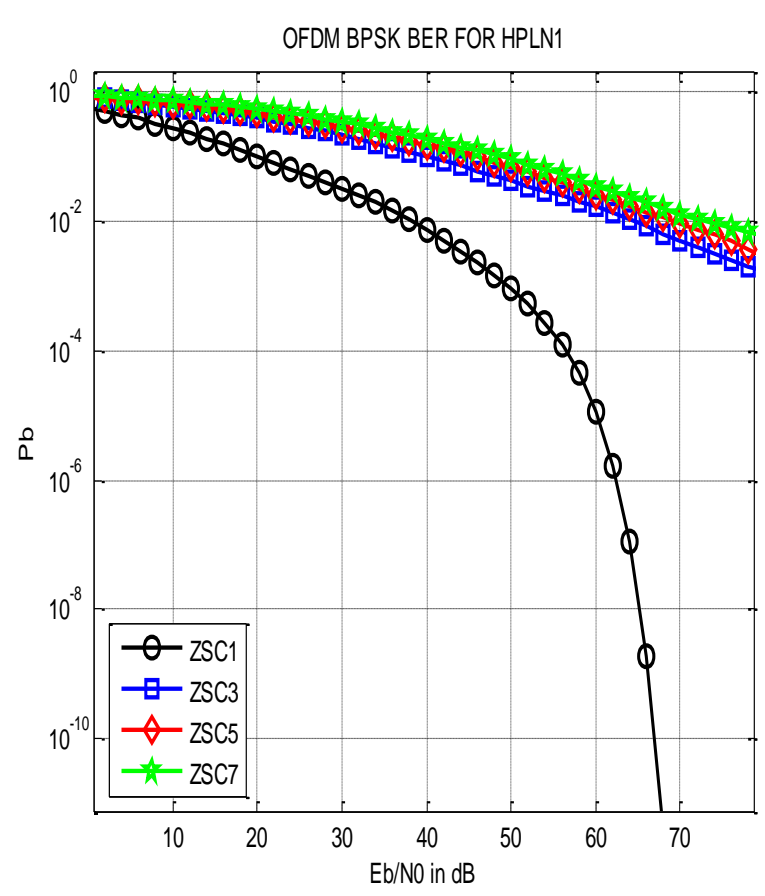

Fig 14: HPLN 1 simulation results at different loads (all terminated at $10 \mathrm{k} \Omega$ )

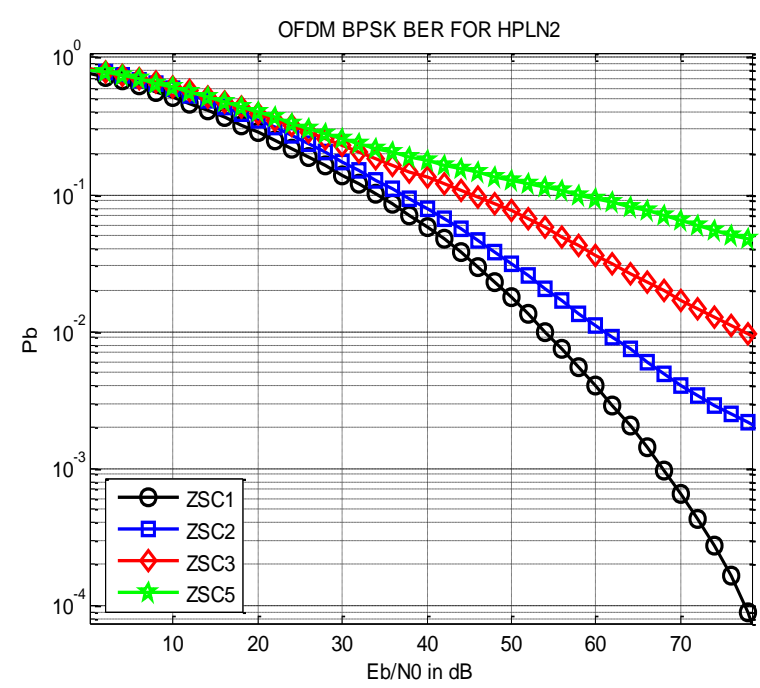

Fig 15: HPLN 2 simulation results at different loads (all terminated at $10 \mathrm{k} \Omega$ )

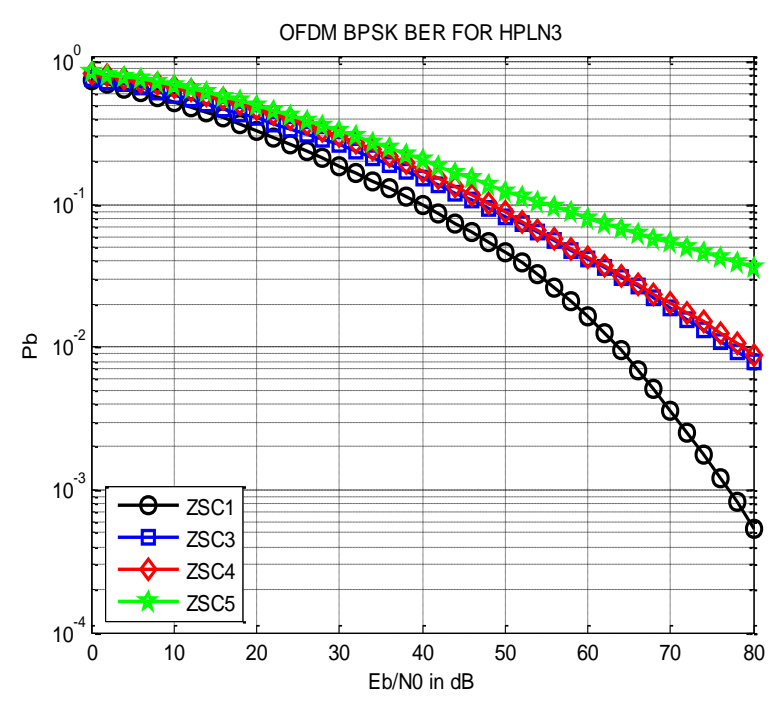

Fig 16: HPLN 3 simulation results at different loads (all terminated at $10 \mathrm{k} \Omega$ ) OFDM BPSK BER FOR HPLN4

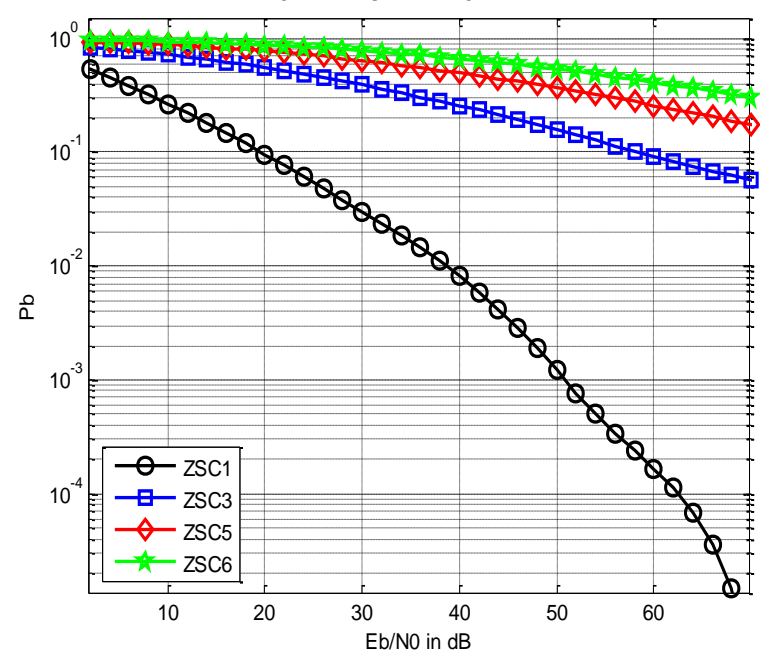

Fig 17: HPLN 4 simulation results at different loads (all terminated at $10 \mathrm{k} \Omega$ ) 


\subsection{Performance Comparison}

By comparing simulations of the un-coded OFDM system it is observed that the performance of OFDM system with BPSK modulation for the considered networks is affected by number of branches and load impedances for each house. This is because when the channel was terminated either in low or high impedances the SNR per bit gain of $24.5 \mathrm{~dB}$, at least $38 \mathrm{~dB}$, at least $47.5 \mathrm{~dB}$ and $35 \mathrm{~dB}$ is required to maintain bit error rate performance of 10-10 at high impedances for HPLN 1, HPLN 2, HPLN 3 and HPLN 4 respectively. This indicates that an average SNR per bit gain of $47.5 \mathrm{~dB}$ is needed so that sustained communication is still maintained in all four topologies.

\section{CONCLUSION}

In this study, the factors that influence the indoor BPLC system design were studied. The channel model by anatory et al has been used to simulate a realistic indoor power-line network of Tanzania. The delay spread of such networks is about $2 \mu$ s and this has been used to calculate the number of sub-carriers and cyclic prefix required in the OFDM system based on BPSK. It was found that, when the channel was terminated either in low or high impedances the average SNR per bit gain of $47.5 \mathrm{~dB}$ is needed so that sustained communication is still maintained in all the four home powerline networks.

\subsection{Recommendations}

The results of this work have shown that communication performance in Tanzania indoor power-line networks is different for each house. To maintain the same performance many houses need to be taken into account. This will help BPLC communication systems engineers to design robust and reliable communication systems. Also without coding the performance is poor because of high SNR required for better performance. To improve performance error control codes are required, to minimize SNR for a particular bit error rate.

\subsection{Suggestions for further research}

For future work it is recommended to perform Tanzania indoor power-line network modeling so that many houses can be investigated. The model will enable the discovery of transmission methods that can cope with different topologies of Tanzania indoor power-line networks. Also there is a need of coming up with a method of deriving the power delay profiles from the power-line channel models like that of Anatory et al.

\section{REFERENCES}

[1] Anatory, J., Kissaka, M. M, and Mvungi, N. H. (2003), "Performance Evaluation of Different MAC Protocols for IP based Power-line Communication Networks in Developing Countries" Proceedings of 7th International Symposium of Power-line Communication and Application, Kyoto, Japan, March.

[2] Glover, I. and Grant, P. (2000), Digital Communications, Europe, Prentice Hall.

[3] Anatory, J., Kissaka, M. M, and Mvungi, N. H. (2005), "Broadband Services Provision in Power-line Communications of Developing Countries", IEEE Explore.

[4] Anatory, J., Kissaka, M. M, and Mvungi, N. H. (2007), "Channel model for broadband power-line communication”, IEEE Trans. Power Del., vol.22, no. 1, January.

[5] Anatory, J., Theethayi, N. and Thottappillil, R. (2009), “A Broadband Power-Line Communication System Design Scheme for Typical Tanzanian Low-Voltage Network", IEEE Trans. Power Del., July.

[6] N. Mtonyole, J. Anatory and A. Mvuma (2012), "Effects of Multipath on MC-CDMA for Broadband Power-line Communications" Journal of Informatics and Virtual Education, ISSN 1821-7087, Vol. 2, No. 01, November 2012, pp 15-23.

[7] Goldsmith, A. (2005), Wireless Communications, Stanford University, Cambridge University Press.

[8] Harada, H. and Prasad, R. (2002), Simulation and Software Radio for Mobile Communications, Artech House.

[9] Held, G. (2006), Understanding broadband over power line, Boca Raton, New York, Auerbach Publications.

[10] Hrasnica, H., Haidine A., and Lehnert R., (2004), Broadband Power-line Communications Networks Design, England, Wiley and Sons.

[11] Home Plug (2012), Home Plug 1.0 Technology White Paper, https://www.homeplug.org/tech/tech_page2/, site visited on February 17, 2012.

[12] Konate, C., Machmoum, M. and Diouris, J. F. (2007), "Multi path Model for Power Line Communication Channel in the Frequency Range of $1 \mathrm{MHz}-30 \mathrm{MHz}$ " EUROCON International Conference on Computer as a Tool, Warsaw, September. 